\title{
Understanding the role of injury/illness sensitivity and anxiety sensitivity in (automatic) pain processing: an examination using the extrinsic affective simon task.
}

Citation for published version (APA):

Vancleef, L. M. G., Peters, M. L., Gilissen, S. M. P., \& de Jong, P. J. (2007). Understanding the role of injury/illness sensitivity and anxiety sensitivity in (automatic) pain processing: an examination using the extrinsic affective simon task. The Journal of Pain, 8, 563-572. https://doi.org/10.1016/j.jpain.2007.02.431

Document status and date:

Published: 01/01/2007

DOI:

10.1016/j.jpain.2007.02.431

Document Version:

Publisher's PDF, also known as Version of record

Document license:

Taverne

Please check the document version of this publication:

- A submitted manuscript is the version of the article upon submission and before peer-review. There can be important differences between the submitted version and the official published version of record.

People interested in the research are advised to contact the author for the final version of the publication, or visit the DOI to the publisher's website.

- The final author version and the galley proof are versions of the publication after peer review.

- The final published version features the final layout of the paper including the volume, issue and page numbers.

Link to publication

\footnotetext{
General rights rights.

- You may freely distribute the URL identifying the publication in the public portal. please follow below link for the End User Agreement:

www.umlib.nl/taverne-license

Take down policy

If you believe that this document breaches copyright please contact us at:

repository@maastrichtuniversity.nl

providing details and we will investigate your claim.
}

Copyright and moral rights for the publications made accessible in the public portal are retained by the authors and/or other copyright owners and it is a condition of accessing publications that users recognise and abide by the legal requirements associated with these

- Users may download and print one copy of any publication from the public portal for the purpose of private study or research.

- You may not further distribute the material or use it for any profit-making activity or commercial gain

If the publication is distributed under the terms of Article $25 \mathrm{fa}$ of the Dutch Copyright Act, indicated by the "Taverne" license above, 


\title{
Understanding the Role of Injury/lllness Sensitivity and Anxiety Sensitivity in (Automatic) Pain Processing: An Examination Using the Extrinsic Affective Simon Task
}

\author{
Linda M.G. Vancleef, * Madelon L. Peters, * Susan M.P. Gilissen, ${ }^{*}$ and Peter J. De Jong ${ }^{\dagger}$ \\ *Department of Clinical Psychological Science, Maastricht University, Maastricht, The Netherlands; and the \\ ${ }^{+}$Department of Clinical and Developmental Psychology, University of Groningen, Groningen, The Netherlands.
}

\begin{abstract}
Three fundamental fears are assumed to underlie psychopathology: Anxiety Sensitivity (AS), Injury/illness sensitivity (IS), and Fear of Negative Evaluation (FNE). Both AS and IS may form risk factors for the development and exacerbation of chronic pain. The current research examines the relation between these fears and automatic threat appraisal for pain-related stimuli. Study $1(n=48)$ additionally examined content-specific associations of AS and FNE with the automatic threat appraisal of, respectively, panic and social evaluative cues. Study $2(n=60)$ additionally focused on the association of IS and AS with the engagement in health protecting behavior, and the use of health care services. Both studies found evidence for an automatic threat appraisal of aversive stimuli. Study 2 demonstrated a positive association between the automatic threat appraisal for pain-related stimuli and individuals' IS levels. IS was found to be the single best predictor of the tendency to engage in health protecting behavior, whereas AS was the single best predictor of the reported use of health care services.
\end{abstract}

Perspective: This study contributes to the field of knowledge on putative risk factors for chronic pain. Results demonstrate an automatic threat appraisal toward pain-related stimuli that is related to vulnerability traits for pain. This automatic threat appraisal might initiate relatively spontaneous (nonstrategic) pain-maintaining behavioral responses.

(c) 2007 by the American Pain Society

Key words: Injurylillness sensitivity, anxiety sensitivity, automatic threat appraisal, EAST.

W hen trying to understand why some people develop chronic pain whereas others do not, an important role is assigned to the presence of vulnerability factors. One such vulnerability factor is anxiety sensitivity (AS). AS is defined as the fear of anxiety symptoms (eg, heart palpitations) arising from the belief that these symptoms will lead to harmful somatic, psychological, or social consequences. ${ }^{26}$ Together with injury/ illness sensitivity (IS) and fear of negative evaluation (FNE), AS is considered to be 1 of the 3 fundamental fears that are assumed to underlie various psychopathological conditions. ${ }^{30}$ AS has been studied mostly as a risk factor for panic disorder. ${ }^{28}$ Yet, since AS is characterized by

Received October 27, 2006; Revised February 16, 2007; Accepted February $27,2007$.

Address reprint requests to Linda M.G. Vancleef, Department of Clinical Psychological Science, Maastricht University, PO Box 616, 6200 MD Maastricht, The Netherlands. E-mail: L.Vancleef@dmkep.unimaas.nl

$1526-5900 / \$ 32.00$

C 2007 by the American Pain Society

doi:10.1016/j.jpain.2007.02.431 dysfunctional cognitions regarding bodily sensations, AS has also been considered as a potential risk factor for maladjustment to (chronic) pain. ${ }^{1,2}$ Accordingly, AS was found to be associated with fear of pain, pain-specific avoidance behavior and elevated medication use in chronic pain patients, and negative pain responses after experimental pain induction. ${ }^{3,18,19}$

IS, defined as exaggerated and excessive worrying about future injury and illness, may be another vulnerability factor for the development of chronic pain and disability. ${ }^{33}$ In support of this, IS was found to be a better predictor for fear of pain and pain catastrophizing than AS and to be the single best predictor of imminent fear of experimentally induced pain. ${ }^{33}$

Besides personality traits, dysfunctional cognitions can be considered as latent vulnerability factors for the chronic course of pain. According to the cognitive-behavioral model of chronic pain, emotional and behavioral responses to pain are largely determined by the interpretation and cognitive appraisal of a situation. ${ }^{25}$ 
Information processing theories state that dysfunctional beliefs and interpretations of innocuous stimuli as threatening form the core of anxiety and affective disorders. ${ }^{4}$ The identification of a personally relevant negative stimulus is assumed to automatically activate a threat-processing template that guides reflexive responses on the basis of the initial threat impression. ${ }^{4}$ Similar processes are assumed to be involved in (fear of) pain. If indeed confrontation with a pain-related stimulus automatically triggers an affective evaluation of this stimulus as threatening, this may subsequently elicit pain-maintaining behaviors and cognitions, contributing to the chronic course of pain.

The automatic evaluation of stimuli can be studied by means of indirect measures such as the Extrinsic Affective Simon Task $\left(\mathrm{EAST}^{9}\right)$. Indirect measures overcome the disadvantage of limited cognitive accessibility and differential self-presentation tendencies inherent to direct, selfreport measures. ${ }^{9,12}$ Moreover, they offer the advantage of studying individuals' automatic and spontaneous responses that putatively differ from their controlled responses. $^{12,17}$

In 2 subsequent studies we used the EAST to examine whether elevated levels of IS and AS are associated with the automatic threat appraisal of pain-related stimuli. Study 1 additionally explored the relation between enhanced levels of the fundamental fears and the contentspecificity of the automatic threat appraisals. Based on the specific content of each fundamental fear, it is expected that FNE and AS will show a strong and unique association with a threat appraisal towards social threat and panic-related stimuli, respectively. Although both IS and AS are hypothesized to be associated with an enhanced threat appraisal toward pain-related stimuli, IS is assumed to show the strongest association with this threat appraisal.

Study 2 zoomed in on the association between AS and IS and automatic threat appraisals of stimuli directly related to health threats. In addition, Study 2 examined the predictive validity of IS and AS for the use of health care services and individuals' self-reported tendency to engage in health protecting behaviors, and the putative additional predictive value of automatic threat appraisals over and above IS and AS.

\section{Study 1}

\section{Method}

\section{Participants}

Forty-eight healthy participants (36 female) with a mean age of 21.8 years (range: 18 to $43, \mathrm{SD}=4.36$ ), recruited at Maastricht University's local community, took part in this study. Inclusion criteria for participation were being in good physical and mental health, and having Dutch as a mother tongue. Colour blindness and dyslexia were exclusion criteria. Compliance with these criteria was verbally checked before making an appointment by asking participants directly whether they were (i) currently free from acute or chronic ( $>3$ months) pain complaints, and (ii) not currently diagnosed as having a mental health disorder. All participants gave informed consent and were financially compensated for their participation. The research proposal was approved by the Ethics Committee of the Academic Hospital Maastricht/Maastricht University.

\section{Materials and Measures}

\section{Extrinsic Affective Simon Task (EAST)}

In the present EAST, coloured target words (panic-related, pain-related, and social evaluation-related nouns) and white attribute words (threatening and neutral adjectives) were presented 1 by 1 on a computer screen. Participants are instructed to respond to the color of the target words (green or blue) and to the content of the white attribute words (threatening or neutral meaning) by pressing a left or a right response button. Participants first practiced with these instructions and the different type of response required during 2 practice phases. In the first practice phase, white attribute words are presented and participants learn to react to the content of the words; 1 button (eg, left) has to be pressed for words with a threatening meaning and the other button (eg, right) for words with a neutral meaning. The assignment of the attribute with either the threatening or neutral meaning to a specific response button results in an intrinsic association between the location of the response button and the attribute meaning (eg, left button becomes associated with threat; right button becomes associated with neutral). In the second practice phase, the coloured target words are presented and participants now learn to respond to the color of the words; 1 button (eg, left) has to be pressed for green words, the other button (eg, right) for blue words. In the subsequent test phase of the EAST white attribute and coloured target words are randomly presented and responses have to be made as learned in the prior practice phases. The coloured target words of the test phase constitute of the critical trials; participants have to respond to colour only and ignore the meaning of these words, but it is assumed that this meaning will be processed automatically. Under this assumption, compatible and incompatible trials can be identified. The compatible trials are those trials in which the response button and the target word share the same evaluative meaning (eg, press the left button for coloured pain-related words), and the incompatible trials are those trials in which the response button and the target word share a contradictive evaluative meaning (eg, press the right button for coloured pain-related words). It is expected that responses will be faster and more accurate on compatible than on incompatible trials.

Panic-related (6), pain-related (6), and social evaluation-related (6) nouns were used as target words in the present EAST. The attributes consisted of threatening (6) and neutral (6) adjectives (Appendix A). All words were presented on a black background on a 17-inch computer 
screen. Before the presentation of each word, a fixation dot appeared during $500 \mathrm{~ms}$ in the centre of the computer screen. Participants responded by pressing the right or the left button of a response box. The time between the onset of the word and the first key press and response accuracy were measured. If the wrong response was given, an error message appeared on the screen, which disappeared after the correct response was given. The next word was presented 1200 ms after a correct response. To counteract potential response location effects, we counterbalanced the location of the required response button over participants, giving 4 different versions of the task. We created a fixed random word list using the following restrictions: (1) the same word was never presented on 2 or more consecutive trials, (2) the same stimulus color never appeared on more than 4 consecutive trials, and (3) the required response was never the same on 4 or more consecutive trials. The task was implemented with MEL V 2.0 and was executed on a Pentium-S, 133 mHz computer (Intel, Santa Clara, CA).

\section{Self-Report Measures}

In correspondence with our previous studies, the 3 fundamental fears (AS, IS, FNE) are assessed by administering 1 questionnaire to participants that combines items from 3 scales that measure each fear separately. ${ }^{32,33}$ As such, this questionnaire incorporates the Anxiety Sensitivity Index (ASI) to measure AS with 16 items that ask about possible negative consequences of experiencing anxiety. IS is assessed with the Injury/illness Sensitivity Index (ISI), of which 6 items pertain to the fear of illness and 5 items refer to the fear of injury. The Brief Fear of Negative Evaluation Scale (BFNE) measures the fear of negative evaluation with 12 items. Participants indicated their degree of agreement with all statements on a 5-point Likert scale, ranging from 1 (not at all agree) to 5 (absolutely agree). The psychometric properties of the English version of the $\mathrm{ASI}^{24}$ the $\mathrm{BFNE},{ }^{7,21}$ and recently the $I S I^{6}$ have well been documented. Internal consistency and 6-month test retest reliability of the ASI, ISI, and BFNE in our combined questionnaire proved to be satisfactory. ${ }^{33}$

\section{Procedure}

Participants were seated behind a PC to perform the EAST and to fill out the questionnaires. All participants started with the implicit measure (ie, EAST) and completed the self-report measures subsequently. ${ }^{5}$ Instructions for the EAST appeared on the screen and encouraged participants to work as fast and accurate as possible. After reading the instructions, participants could initiate the task by pressing a button on the response box. In the first practice phase, the 12 attribute words were each presented twice in a random order. In the second practice phase, the 18 target words were each presented twice-once in each color-in a random order. The test phase consisted of 60 trials, presenting all attribute and target words twice. The whole task con- sisted of 120 trials, and it took about 15 minutes to complete the task. The experimenter followed task progress in an adjacent room.

\section{Analytical Plan}

Data analyses were conducted on the colored trials from the EAST test phase only. Because affective Simon effects are known to emerge in error data as well, analyses were performed on both the reaction time data and the error percentages. ${ }^{9}$ For the reaction time analyses, only reaction times on trials with a correct first response were taken into account. Following the recommendations made by Greenwald, McGhee, and Schwartz, ${ }^{14}$ reaction times below $300 \mathrm{~ms}$ and above $3000 \mathrm{~ms}$ were set at $300 \mathrm{~ms}$ and $3000 \mathrm{~ms}$ respectively, and all reaction times were log-transformed (log-rt). For reasons of clarity, however, raw reaction times are used when presenting means and standard deviations. ${ }^{9}$

Mean reaction times and error percentages were calculated for the "compatible" trials and for the "incompatible" trials. Next, a 3 (category: pain vs panic vs social evaluation) $\times 2$ (compatible vs incompatible) repeatedmeasures ANOVA was conducted on the log-rt and the errors. The automatic threat appraisal was further examined with paired $t$ tests for each category separately. Next, an EAST score was calculated by subtracting the mean compatible score from the mean incompatible score for each target category separately, for both the reaction times (EAST-rt) and the errors (EAST-error). A positive EAST-score reflects a threatening appraisal of the target category. Correlations between the self-report measures and the EAST scores are computed with Pearson correlation coefficients.

\section{Results}

Descriptive statistics for the target categories are presented in Table 1 . The $3 \times 2$ ANOVA on the log-rt revealed a main effect of compatibility $(F(1,47)=9.92, P=$ $.003, d=0.17)$. Participants responded generally faster when the required response was associated with a threatening meaning (compatible trials; $M=662$, sd $=109$ ) than when it was associated with a neutral

Table 1. Mean Reaction Times (in ms) and Mean Error Percentages (SD) on Compatible and Incompatible Trials, Calculated Separately for the Three Target Categories $(\mathrm{n}=48)$

\begin{tabular}{|c|c|c|c|c|}
\hline & \multicolumn{2}{|c|}{ REACTION TIME } & \multicolumn{2}{|c|}{ ERROR PERCENTAGE } \\
\hline & COMPATIBLE & INCOMPATIBLE & COMPATIBLE & INCOMPATIBLE \\
\hline Panic & $654(124)$ & $699(147)$ & $9(14)$ & $11(19)$ \\
\hline Pain-related & $661(139)$ & $711(181)$ & $10(14)$ & $9(15)$ \\
\hline $\begin{array}{l}\text { Negative } \\
\text { evaluation }\end{array}$ & $672(136)$ & $692(155)$ & $9(13)$ & $7(11)$ \\
\hline
\end{tabular}


Table 2. Descriptive Statistics for the Self-Report Measures and Bivariate Pearson Correlation Coefficients Between the EAST Scores for the Three Target Categories and the Scores on the Self-Report Measures $(n=48)$

\begin{tabular}{|c|c|c|c|c|c|c|c|c|c|c|}
\hline & \multicolumn{10}{|c|}{ DESCRIPTIVES } \\
\hline & $\operatorname{MEAN}(S D)$ & RANGE & $A S I$ & BFNE & $\begin{array}{c}\text { EAST-RT } \\
\text { PAIN }\end{array}$ & $\begin{array}{c}\text { EAST-RT } \\
\text { PANIC }\end{array}$ & $\begin{array}{c}E A S T-R T \\
\text { NEG. EVAL }\end{array}$ & $\begin{array}{c}\text { EAST-ERR } \\
\text { PAIN }\end{array}$ & $\begin{array}{c}\text { EAST-ERR } \\
\text { PANIC }\end{array}$ & $\begin{array}{l}\text { EAST-ERR } \\
\text { NEG. EVAL }\end{array}$ \\
\hline$|S|$ & $23.92(8.34)$ & $13-48$ & $0.66^{*}$ & 0.13 & 0.06 & 0.17 & 0.19 & -0.09 & -0.07 & -0.02 \\
\hline$\left.A S\right|^{a}$ & $11.19(7.05)$ & $1-36$ & 1 & $0.43^{*}$ & 0.25 & 0.12 & 0.10 & -0.10 & -0.17 & 0.16 \\
\hline BFNE & $27.40(9.86)$ & $12-55$ & & 1 & -0.04 & 0.10 & -0.00 & 0.02 & -0.07 & $0.39 *$ \\
\hline
\end{tabular}

Abbreviations: EAST-rt, the EAST score for the log-transformed reaction times; EAST-err, the EAST score for the error percentage; ASI, Anxiety Sensitivity Index; ISI, Injury/illness Sensitivity Index; BFNE, Brief Fear of Negative Evaluation Scale.

aBecause the scoring format of the ASI in this study (1-5) deviates from the original ASI (0-4), we transformed ASI scores to correspond with the original scale to enhance comparability with other research reporting about the ASI.

$* P<.01$.

meaning (incompatible trials; $M=701, \mathrm{sd}=139$ ). There was no main effect of category $(F(2,46)=.26, P=.77)$, nor an interaction effect of category $x$ compatibility $(F(2,46)=1.28, P=.28)$. The repeated measures ANOVA on the error data revealed no significant effects.

Although the ANOVA revealed a nonsignificant interaction, inspection of the raw mean scores in Table 1 indicates differences within categories. Post hoc $t$ tests demonstrated significant faster responses on compatible trials for the panic category, $t(48)=-2.35, P=.023$, the pain-related category, $t(48)=-2.99, P=.004$, but not for the negative evaluation category, $t(48)=-0.67, P=$ .51. Table 2 presents descriptive statistics of the ASI, ISI, and BFNE, and Pearson correlations with the EAST scores. Only the correlation between the EAST-error score and the BFNE reached significance.

Following De Houwer, ${ }^{9}$ the reliability of the EAST was determined by calculating the correlations between the EAST-scores on the first and the second half of the experimental test phase for each category. For the log-rt data, this resulted in a significant correlation for the panic words only, $r=0.35, P=.015$. The correlations for the pain-related words $(r=-0.042)$ and the social evaluation words $(r=0.21)$ were not significant. The same pattern emerged from the error data, $r=0.44, P=.002$ for the panic words and nonsignificant correlations for the pain-related $(r=0.09)$ and the social evaluation words $(r=0.12)$.

\section{Discussion}

Results indicate the presence of an automatic threat appraisal toward the pain-related and panic-related words. However, no evidence emerged to sustain the idea that this threat appraisal relates to the presence of elevated levels of AS or IS. Likewise, no evidence emerged for a specific relation between AS levels and a threat appraisal for panic-related stimuli. However, although no significant EAST effect is found for the negative evaluation category, the EAST-error score of this category is the only score that correlates positively with FNE. This might be due to the affective value of the stimulus words. The words that represent the social evaluation category are more ambiguous of nature (eg, stranger), probably only triggering negative affective valence for those who are especially sensitive to the negative content of these words. The pain-related and the panic stimuli on the other hand, have a generally negative affective valence (eg, heart palpitation, physician), which might make it difficult to reveal individual variability. The ability to detect these individual differences might require a more sensitive EAST than the current one.

We therefore conducted a second study, in which we modified the EAST so that it became a more sensitive tool to study the hypothesized association between an automatic threat appraisal for stimuli that are reflective of pain, injury, and illness, and individual differences in IS and AS levels. Study 2 furthermore incorporates 2 measures that contribute to studying the predictive value of IS and AS for health related behaviors, namely the use of health care services and the self-reported tendency to engage in health protecting behavior.

\section{Study 2}

\section{Method}

\section{Participants}

Sixty participants (46 female) with a mean age of 22.6 years (range: $18-47$; SD $=5.64$ ), recruited at the local community of Maastricht University participated in Study 2. Inclusion and exclusion criteria were identical to Study 1, with the additional exclusion criterion of prior participation in Study 1. All participants gave informed consent and received financial compensation for participating. Due to technical problems, the EAST data from 2 participants were missing, and data analyses were conducted on 58 participants. The research protocol was approved by the internal ethical review committee of the research institute Experimental Psychopathology (EPP). 


\section{Materials and Measures}

\section{EAST}

The EAST was modified in order to obtain a more sensitive measure of the automatic threat appraisal. ${ }^{9}$ First, we focussed on pain-related stimuli only. This allowed us to incorporate more compatible and incompatible trials in the test phase of the EAST, increasing task reliability without affecting task duration. It has been suggested that the EAST yields more reliable and accurate results as more trials are included, but the advantage of more trials needs to be weighed against the potential disadvantage of boredom and fatigue that may accompany long tasks. ${ }^{9,31}$ Second, because it has been suggested that in priming measures such as the EAST, associations are being activated on basis of the exemplars of a target category rather than category labels we replaced some target words. ${ }^{8}$ Replacements were based on a pilot in which 15 volunteers rated the degree to which putative stimuli words were representative for the categories injury or illness, threat or safety. Third, we changed the unipolar attribute dimension (ie, neutral-threatening) into a bipolar attribute dimension (ie, safe-threatening). Finally, we changed the software that delivered the EAST from MEL to E-Prime (Psychology Software Tools, Inc., Pittsburgh, PA). The better clock facilities of E-prime may contribute to the task's sensitivity as well.

The target category in the EAST consisted of 6 nouns, referring to illness (eg, cancer), injury (eg, invalid), and pain (eg, wound). The attribute categories consisted of 6 "threatening" words and 6 "safe" words (Appendix A). In the first practice phase, each attribute word was presented 3 times, resulting in 36 trials. The second practice phase consisted of 12 trials presenting each target word once in each color. In accordance with De Houwer, ${ }^{9}$ the test phase started with 2 warm-up trials that were randomly chosen from the attribute list. Next, target words were presented 3 times in each color, and the attribute words were presented equally often as the colored words. Increasing the number of attribute words in the test phase helps to maintain and strengthen the association between the response buttons and the assigned attribute, increasing task sensitivity as well. Following the recommendations of De Houwer, ${ }^{9} 2$ identical test blocks were presented consecutively, creating the possibility to check for eventual boredom or fatigue effects.

The test phase consisted of 148 trials ( 2 identical blocks of 74 trials), and the entire EAST consisted of 196 trials, taking about 20 minutes to complete. Counterbalancing principles, presentation times, and randomization restrictions were applied conform Study 1. The task was executed on a Pentium-S, 133-mHz computer (Intel) in a laboratory setting.

\section{Self-Report Measures}

Anxiety sensitivity and Injury/illness sensitivity were measured with the ASI and ISI (Study 1).

Health protecting behavior. Individuals' tendency to act in a health-protecting manner was assessed with 12 vignettes that were created for this study (Appendix
B). Each vignette contains a description of a situation that implies a certain health risk. Respondents need to imagine themselves being in these particular situations. The description is then followed by a question that asks about a health-protecting behavior that can be posed as a reaction to the described situation. The vignettes cover 2 groups of health protecting behaviors; ie medical help seeking behavior (6 descriptions) and escape/avoidance behavior (6 descriptions). Participants have to indicate the degree of certainty with which they belief they would engage in the proposed behavior ("definitely not"; "probably not"; "probably"; "certainly"). The answers to each question are scored from 1 to 4 , with higher scores on the vignettes indicating more engagement in the health protecting behavior. The internal consistency of the vignette list was satisfactory (Cronbach's $\alpha=0.66$ ).

Use of health care services. A second behavioral measure in this study was obtained by administering a self-created 6-item questionnaire, inquiring for the use of health care services in the last 12 months. Three items referred to the number of visits to the general practitioner and the over-the-counter and prescription medication usage in the past 3 months. The other 3 items referred to the number of visits to a medical specialist, a physical or manual therapist, and an alternative healer in the past 12 months. The questions could be answered by choosing between 4 alternatives that quantified the use of the specific health care service ("not at all"; "once or twice"; "three or four times"; and "more than four times"). The answers are scored from 1 to 4 , and a sum score is calculated with higher scores indicating more use of health care services.

\section{Procedure}

The procedure was largely the same as in Study 1. On termination of the EAST, participants completed the vignettes, the use of health care questionnaire, the ASI, and the ISI.

\section{Analytical Plan}

Data preparation followed the same procedure as in Study 1. After calculating compatible and incompatible scores, analyses were performed on the log-rt and the error percentages with a 2 (evaluative response: compatible vs incompatible) $\times 2$ (experiment half: half 1 vs half 2 ) repeated-measures ANOVA. Paired $t$ tests examined whether participants were faster and more accurate on compatible trials than on incompatible trials, and EAST scores (EAST-rt and EAST-error) were computed. Next, scores on the ISI, the ASI, the vignettes, and the use of health care services were correlated with each other and with the EAST scores using Pearson correlation coefficients. To examine the contribution of AS and IS in the explanation of the automatic threat appraisal we carried out linear regression analyses with AS and IS as the independent variables and EAST scores as the dependent. Next, separate linear regression analyses were performed with the vignette scores and the use of health 
Table 3. Descriptive Statistics for the Self-Report Measures, the Use of Health Care Services, and Health-Protecting Behavior $(n=60)$ and Pearson Correlation Coefficients With the EAST Scores $(n=58)$

DESCRIPTIVES

\begin{tabular}{|c|c|c|c|c|c|c|c|}
\hline & $\operatorname{MEAN}(S D)$ & RANGE & $A S I$ & $\begin{array}{c}\text { USE HeALTH CARE } \\
\text { SERVICES }\end{array}$ & $\begin{array}{c}\text { HeALTH PROTECT } \\
\text { BEHAVIOR } \\
\end{array}$ & EAST-RT & EAST-ERR \\
\hline$|S|$ & $22.05(8.38)$ & $11-47$ & $0.58 *$ & 0.00 & $0.44^{*}$ & $0.29+$ & -0.00 \\
\hline$A S I^{a}$ & $8.28(6.86)$ & $0-40$ & 1 & $0.42 *$ & $0.38^{*}$ & $0.24 \ddagger$ & -0.02 \\
\hline Use health care services & $9.22(2.30)$ & $6-15$ & & 1 & $0.28+$ & 0.12 & 0.08 \\
\hline Health-protect behavior & $28.65(4.87)$ & $19-43$ & & & 1 & $0.22 \ddagger$ & $0.25 \ddagger$ \\
\hline
\end{tabular}

Abbreviations: EAST-rt, the EAST score for the log-transformed reaction times; EAST-err, the EAST score for the error percentage; ASI, Anxiety sensitivity Index; ISI, Injury/illness Sensitivity Index.

a Because the scoring format of the ASI in this study (1-5) deviates from the original ASI (0-4), we transformed ASI scores to correspond with the original scale to enhance comparability with other research reporting about the ASI

${ }^{*} P<.01 ; \dagger P<.05 ; \ddagger P<.10$

care services as the dependent variables. In the first step of this regression analysis, AS and IS were entered as predictors. The implicit threat appraisal score was entered in the second step to test whether the implicit measure had additional predictive value for both behavioral measures.

\section{Results}

Mean reaction times and error percentages were calculated for the compatible $\left(M_{r t}=618, \mathrm{sd}=136 ; M_{\text {error }}=\right.$ 4.07, $s d=4.83)$ and the incompatible trials $\left(M_{r t}=631\right.$, $s d=113 ; M_{\text {error }}=8.33, \mathrm{sd}=6.80$ ). The 2 (compatible vs incompatible) $\times 2$ (half 1 vs half 2 ) ANOVA revealed a main effect of experiment half $(F(1,57)=5.38, P=0.024$, $d=0.086)$ for the log-rt, with faster responses in the second half than in the first half of the experiment, and a main effect of compatibility for the $\log -r t(F(1,57)=$ $5.21, P=.026, d=0.084)$ and the errors $(F(1,57)=19.53$, $P=.000, d=0.25)$. The interaction between compatibility and experiment half was not significant.

Table 3 shows the descriptive statistics for the self-report measures, the vignettes, and the use of health care services questionnaire. The correlation matrix in Table 3 shows a positive correlation between the EAST-rt and the ISI, indicating that higher levels of IS were associated with stronger automatic threat associations. The correlation with the ASI was marginally significant $(P=.066)$. The correlations between the EAST-error and the ISI or the ASI were not significant. The predictive value of IS and AS for the EAST-rt was examined by entering both measures in a linear regression analysis. The resulting model did not reach significance $(F(2,55)=2.79, P=.07$, $R^{2}=.09, R^{2}$ adjusted $\left.=0.06\right)$, with $\beta=0.12, t=0.741, P=$ .46 for AS as predictor, and $\beta=0.22, t=1.42, P=.16$ for IS as predictor. When the same analysis was conducted on the error data, again neither AS or IS proved significant predictors.

The reliability of the EAST was calculated as in Study 1, showing a significant correlation between the first and the second experimental half, $r=0.36, P=.005$ for the log-rt data. The correlation that was calculated within the error data did not reach significance $(r=0.19)$.

Table 3 also shows that the vignette scores correlate positively and significantly with both IS and AS, whereas the use of health care services correlates significantly with AS only. Furthermore, the EAST-rt showed a marginally significant $(P=.094)$ correlation with the score on the vignettes. Table 4 presents the results of the regression analyses on the behavioral measures. Entering both IS and AS as predictors of health protecting behavior

Table 4. Summary Statistics of the Regression Analyses With the ASI, the ISI, and EAST-rt as Predictors of Health-Protecting Behavior and the Use of Health Care Services ${ }^{a}$

\begin{tabular}{|c|c|c|c|c|c|c|}
\hline DEPENDENT & VARIABLE & $B$ & $S E B$ & $B$ & $T$ & $P$ \\
\hline \multicolumn{7}{|c|}{ Health-protecting behavior (Analysis 1) } \\
\hline \multirow[t]{2}{*}{ Step 1} & ASI & 0.13 & 0.10 & 0.19 & 1.31 & 0.20 \\
\hline & ISI & 0.19 & 0.09 & 0.33 & 2.28 & 0.03 \\
\hline \multirow[t]{3}{*}{ Step 2} & ASI & 0.13 & 0.10 & 0.19 & 1.29 & 0.22 \\
\hline & ISI & 0.19 & 0.09 & 0.33 & 2.24 & 0.04 \\
\hline & EAST-rt & 4.47 & 6.36 & 0.09 & 0.70 & 0.48 \\
\hline \multicolumn{7}{|c|}{ Use of health care services (Analysis 2) } \\
\hline \multirow[t]{2}{*}{ Step 1} & ASI & 0.17 & 0.05 & 0.51 & 3.44 & 0.001 \\
\hline & $|S|$ & -0.00 & 0.04 & -0.16 & -1.07 & 0.29 \\
\hline \multirow[t]{3}{*}{ Step 2} & ASI & 0.17 & 0.05 & 0.50 & 3.37 & 0.001 \\
\hline & $|S|$ & -0.00 & 0.04 & -0.17 & -1.12 & 0.27 \\
\hline & EAST-rt & 1.19 & 3.04 & 0.05 & 0.40 & 0.69 \\
\hline
\end{tabular}

NOTE. Analysis 1 , Step $1 R^{2}=0.19$, Step $2 \Delta R^{2}=0.007$. Analysis 2, Step 1 $R^{2}=0.19$, Step $2 \Delta R^{2}=0.002$.

Abbreviations: ASI, Anxiety Sensitivity Index; ISI, Injury/illness Sensitivity Index; EAST-rt, EAST score for the log-transformed reaction times.

Significant predictors are presented in bold.

a Regression analyses were performed with an EAST-index as implicit variable as well, which was calculated as the average of the $z$-transformed rt scores and the $z$-transformed error scores and is suggested to counteract possible speed-accuracy variations, resulting in maximized predictive power of the EAST. Results of the regression analysis did not deviate from the results presented with the rt scores, however. 
resulted in an overall significant model $(F(2,55)=7.66$, $P=.001, R^{2}=0.22, R^{2}$ adjusted $\left.=0.19\right)$ with IS being the only significant predictor ( $\beta=0.33, t=2.28, P=.027)$. Entering the EAST-rt in the second step of the analysis did not significantly add explanatory variance to the scores on the vignettes $\left(F(3,54)=5.22, P=.003, R^{2}=\right.$ $0.22, R^{2}$ adjusted $=0.18 ; \Delta F(1,54)=0.50, P=.48, \Delta R^{2}=$ .007). The regression analysis on the use of health care services showed significance for the overall model when AS and IS were entered in the first step of the analysis ( $F$ $(2,55)=6.52, P=.003, R^{2}=0.19, R^{2}$ adjusted $\left.=0.16\right)$, with AS being the only significant predictor $(\beta=0.51, t=$ $3.44, P=.001)$. The EAST-rt score could not explain additional variance $\left(F(3,54)=4.33, P=.008, R^{2}=0.20, R^{2}\right.$ adjusted $\left.=0.15 ; \Delta F(1,54)=0.15, P=.70, \Delta R^{2}=0.002\right)$.

\section{General Discussion}

Results of both studies showed that aversive stimuli (either pain-related or panic-related) automatically elicit threat associations. The strength of these threat associations appeared independent of individuals' specific fear levels. The latter finding may be explained by the fact that the pain- and panic-related words in the current task hold a generally negative or threatening affective connotation. Therefore, it is likely that irrespective of specific fears people will have negative attitudes toward these stimuli, and previous research using similar implicit tasks showed that general threat words may elicit automatic threat associations irrespective of prior fear. ${ }^{10} \mathrm{Sim}$ ilarly, Goubert et al $^{13}$ report about a general implicit negative attitude towards back-stressing pictures in healthy individuals, using an affective priming task. In Study 2, we implemented several modifications to the EAST to obtain a more sensitive measure. To check if the modifications were beneficial for the reliability of the measure, we examined split-half reliabilities of the EAST effects, demonstrating an increase in the reliability from Study $1(-0.042)$ to Study $2(0.36)$ for the EAST effect on the pain-related target category.

As hypothesized, Study 2 demonstrated that higher IS levels were associated with more pronounced automatic threat appraisals of health-threatening stimuli. A similar relationship between AS and automatic threat appraisal did not reach significance although a trend was observed. It should be acknowledged, however, that the target words in Study 2 were chosen in such a way that they captured 'pain-related targets' that are relevant for a healthy population (ie, injury, illness, and general pain stimuli). This choice has the drawback that these words are less content-specific for AS. Using highly specific targets that referred to anxiety-related sensations (eg, breathless, palpitation), it was recently found that high AS individuals automatically associated these stimuli with harmful health consequences. ${ }^{22}$ So, it seems that the automatic elicitation of threat appraisals depend on whether stimuli are used that correspond to the current concerns of the individual. Although the importance of current concerns in the occurrence of specific cognitive biases was already demonstrated in previous studies, ${ }^{27}$ the suggestion of automatic elicitation of content-specific cognitive bias conflicts with the assumption that automatic negative biases do not show content-specificity. ${ }^{23}$

Up to now, only a few studies have looked into automatic processing biases in relation to chronic pain. These studies gave evidence for negative biases at the strategical, but not at the automatic level. ${ }^{29}$ Further research is necessary to establish the robustness and conditional circumstances of the operation of automatic biases in chronic pain. As such, it remains to be established if AS and IS also relate to automatic threat appraisals when target words are specific for chronic pain, like sensory pain (eg, stabbing, pulsating), or emotional pain (eg, unbearable, killing). However, since the present target words were already closely connected to the central cue of chronic pain (ie, pain), it seems safe to predict that automatic threat appraisals will extend to specific pain stimuli as well.

It might be that AS and IS relate to different aspects of biased processing of information in which pain is somehow involved. IS has been identified by prior research as the single best predictor of fear of imminent pain prior to a pain induction procedure, ${ }^{33}$ whereas AS has been found to be associated with more pain following pain induction, ${ }^{18-20}$ and elevated analgesic use in chronic pain patients. ${ }^{1,2,34}$ Consistent with this IS in the present study was found to be the single best predictor of the engagement in health protecting behavior, whereas AS was the sole predictor for the use of health care services. Hence the present findings stimulate further speculation on the specific predisposing role that both constructs may play in the pain process. Since IS embodies worrying about getting injured or becoming ill, it refers to the expected catastrophic consequences of future pain experiences. Likewise, the vignettes tap individuals' opinion on how they will react should they ever encounter the described situation, thereby mirroring future-oriented behavior. In contrast, AS refers to the negative consequences of current bodily sensations. The use of health care services reflects action that one undertakes in response to experienced bodily sensations. Thus, the present findings add to the idea that IS and AS may be relevant for explaining complementary aspects of pain-related behaviors, and it seems worthwhile to study further their potentially differential contribution to the chronic course of pain. Following on from this, it would be interesting to test in future research whether IS will be most predictive of automatic threat appraisals for stimuli specifically referring to future physical harm (eg, disability) and AS for automatic threat appraisals when stimuli are used that describe common and 'daily' painful sensations (eg, pain, cramp, headache).

Earlier studies using the affective Simon test in the context of substance abuse and specific phobia not only demonstrated that implicit attitudes (reflexive associations) can diverge from explicit attitudes (reflective associations), ${ }^{16}$ they also showed that implicit associations with complaint-related stimuli have predictive value for problem behaviors over and above explicit attitudes ${ }^{11,16}$ and have superior predictive value for relatively sponta- 
neous (nonreflective) problem behaviors. ${ }^{17}$ In apparent contrast, the EAST-effects in the present study showed no additional predictive power in predicting health behavior. One testable explanation for the absence of additional predictive value in the present study might be that implicit and explicit associations with respect to health threats are less discrepant than with respect to alcohol and spiders. In addition, it might be that relatively spontaneous (reflexive) behaviors are less important in the context of health threats than in the context of phobic complaints and substance misuse. If so, health behaviors would be guided predominantly by explicit considerations that can be more efficiently tapped by means of self-report measures than by performance measures such as the EAST. However, because in the present study health behaviors were explicitly measured using self-report measures rather than observation or physiological measurement it seems more plausible to assume that the behavioral measures did simply not capture spontaneous behaviors that are assumed to be guided by automatic associations. ${ }^{17}$ To more definitely settle this issue it would be necessary to include indirect measures of strategic and spontaneous pain-related behaviors (eg, reflexive increase in muscle tension when confronted with potential pain-related threat) in future research. $^{35}$

Apart from the lack of an objective behavioral measure, several other limitations need to be considered when interpreting the current results. Relatively few studies have used the EAST to examine the relation between automatic associations and individual levels of personality constructs such as anxiety, stressing the need for replication of the current findings. Moreover, several authors report about unsatisfactory reliability of the $\mathrm{EAST}^{31}$ and this concords with the low split-half reliability that was observed in Study 1. Nevertheless, Study 2 illustrates the possibility to create a more reliable and sensitive EAST by extending the number of trials and by modifying target category and attributes. ${ }^{16}$ In addition, evidence exists that the EAST can be sensitive enough to

\section{References}

1. Asmundson GJ, Norton GR: Anxiety sensitivity in patients with physically unexplained chronic back pain: a preliminary report. Behav Res Ther 33:771-777, 1995

2. Asmundson GJG, Wright KD, Hadjistavropoulos HD: Anxiety sensitivity and disabling chronic health conditions: State of the art and future directions. Scand J Behav Ther 29:100117,2000

3. Asmundson GJG, Wright KD, Norton PJ, Veloso F: Anxiety sensitivity and other emotionality constructs in predicting headache medication use in patients with recurring headaches: implications for abuse and dependency. Addict Behav 26:827-840, 2001

4. Beck AT, Clark DA: An information processing model of anxiety: Automatic and strategic processes. Behav Res Ther 35:49-58, 1997 predict actual behavior ${ }^{15,16}$ and to differentiate between individuals with and without anxiety complaints. ${ }^{22}$ Furthermore, the tendency to engage in health protecting behavior was measured with situational descriptions that were developed for the current study, and further validation of this measure is recommendable. Finally, it cannot be ruled out that participants' current physical or mental conditions may have affected task performance, since compliance with in- and exclusion criteria were only queried when participants were scheduled for a test appointment, and not on the day of testing itself. Furthermore, we did not use validated questionnaires to assess participant's mental or physical state. In addition, despite the fact that the shift in programming software from the first to the second study is assumed to contribute to the measure's sensitivity, caution is warranted when comparing data between both studies because differences might be partly attributable to the programming software.

To conclude, the present study stresses the need for further research of biases in information processing that may originate from fast and automatic associations in memory. Furthermore, it opens the way for further research on the relation between automatic evaluations of pain-related situations and specific pain behavior, such as escape and avoidance behaviors that are frequently observed in chronic pain patients. Finally, the current study provides evidence for the importance of both IS and $A S$ as vulnerability factors in pain processing, suggesting that both constructs may account for different aspects of the pain process.

\section{Acknowledgments}

This research was supported by a grant from the Netherlands Organization for Scientific Research (NWO: 015001-050). The authors are grateful to Charlie Bonnemayer for technical help and support in programming and implementing the EAST.

5. Bosson JK, Swann WB, Pennebaker JW: Stalking the perfect measure of implicit self-esteem: the blind man and the elephant revisited? J Pers Soc Psychol 27:631-643, 2000

6. Carleton NR, Asmundson GJ, Taylor S: Fear of physical harm: factor structure and psychometric properties of the injury/lllness sensitivity index. J Psychopathol Behav Assess 27:235-241, 2005

7. Carleton NR, McCreary DR, Norton PJ, Asmundson GJG: Brief fear of negative evaluation scale-revised. Depress Anxiety 23:297-303, 2006

8. De Houwer J: A structural and process analysis of the Implicit Association Test. J Exp Soc Psychol 37:443-451, 2001

9. De Houwer J: The extrinsic affective Simon task. Exp Psychol 50:77-85, 2003

10. de Jong PJ, Hout van den MA, Rietbroek H, Huijding J: Dissociations between implicit and explicit attitudes toward phobic stimuli. Cognition Emotion 17:521-545, 2003 
11. de Jong PJ, Wiers RW, van den Braak M, Huijding J: Using the Extrinsic Affective Simon Test as a measure of implicit attitudes toward alcohol: Relationship with drinking behavior and alcohol problems. Addict Behav 32:881-887, 2007

12. Fazio RH, Olson MA: Implicit measures in social cognition research: their meaning and use. Annu Rev Psychol 54: 297-327, 2003

13. Goubert L, Crombez G, Hermans D, Vanderstraeten G: Implicit attitude towards pictures of back-stressing activities in pain-free subjects and patients with low back pain. Eur J Pain 7:33-42, 2003

14. Greenwald AG, McGhee DE, Schwartz JLK: Measuring individual differences in implicit cognition: an affective priming study. J Pers Soc Psychol 74:1464-1480, 1998

15. Houben RMA, Gijsen A, Peterson J, De Jong PJ, Vlaeyen JWS: Do health care providers' attitudes towards back pain predict their treatment recommendations? Differential predictive validity of implicit and explicit measures. Pain 114: 491-498, 2005

16. Huijding J, De Jong PJ: A pictorial version of the Extrinsic Affective Simon Task: sensitivity to generally affective and phobia-relevant stimuli in high and low spider fearful individuals. Exp Psychol 52:289-295, 2005

17. Huijding J, de Jong PJ: Specific predictive power of automatic spider-related affective associations for controllable and uncontrollable fear responses toward spiders. Behav Res Ther 44:161-176, 2006

18. Keogh E, Birkby J: The effect of anxiety sensitivity and gender on the experience of pain. Cognition Emotion 13: 813-829, 1999

19. Keogh E, Mansoor L: Investigating the effects of anxiety sensitivity and coping on the perception of cold pressor pain in healthy women. Eur J Pain 5:11-22, 2001

20. Lang AJ, Sorrell JT, Rodgers W, Lebeck MM: Anxiety Sensitivity as a predictor of labor pain. Eur J Pain 10:263-270, 2006

21. Leary MR: A brief version of the fear of negative evaluation scale. Pers Soc Psychol Bull 9:371-375, 1983

22. Lefaivre MJ, Watt MC, Stewart SH, Wright KD: Implicit associations between anxiety-related symptoms and catastrophic consequences in high anxiety sensitive individuals. Cogn Emotion 20:295-308, 2006
23. Mathews A, MacLeod C: Cognitive approaches to emotion and emotional disorders. Annu Rev Psychol 45:25-50, 1994

24. Peterson RA, Heilbronner RL: The anxiety sensitivity index: construct validity and factor analytic structure. J Anx Disord 1:117-121, 1987

25. Pincus T, Morley S: Cognitive-processing bias in chronic pain: A review and integration. Psychol Bull 127:599-617, 2001

26. Reiss S, Peterson RA, Gursky DM, McNally RJ: Anxiety sensitivity, anxiety frequency and the prediction of fearfulness. Behav Res Ther 24:1-8, 1986

27. Riemann BC, McNally RJ: Cognitive processing of personally relevant information. Cogn Emotion 9:325-340, 1995

28. Schmidt NB, Cook JH: Effects of anxiety sensitivity on anxiety and pain during a cold pressor challenge in patients with panic disorder. Behav Res Ther 37:313-323, 1999

29. Snider BSMA, Asmundson GJG, Wiese KC: Automatic and strategic processing of threat cues in patients with chronic pain: a modified-Stroop evaluation. Clin J Pain 16 144-154, 2000

30. Taylor S: The structure of fundamental fears. J Behav Ther Exp Psychiatry 24:289-299, 1993

31. Teige S, Schnabel K, Banse R, Asendorpf JB: Assessment of multiple implicit self-concept dimensions using the extrinsic affective Simon task (EAST). Eur J Pers 18:495-520, 2004

32. Vancleef LMG, Peters ML: Pain catastrophizing, but not injury/lllness sensitivity or anxiety sensitivity, enhances attentional interference by pain. J Pain 7:23-30, 2006

33. Vancleef LMG, Peters ML, Roelofs J, Asmundson GJG: Do fundamental fears differentially contribute to pain-related fear and pain catastrophizing? An evaluation of the sensitivity index. Eur J Pain 10:527-536, 2006

34. Vincent N, Walker J: Anxiety Sensitivity: Predictor of sleep-related impairment and medication use in chronic insomnia. Depress Anxiety 14:238-243, 2001

35. Vlaeyen JWS, Seelen $H$, Peters ML, De Jong PJ, Aretz E, Beisiegel E, Weber WEJ: Fear of movement/(re)injury and muscular reactivity in chronic low back pain patients: An experimental investigation. Pain 82:297-304, 1999

\section{Appendix A. Target and Attribute Words in Study 1 and Study $2^{\text {a }}$}

$$
\text { STUDY } 1
$$

STUDY 2

Target words Panic-related: Hart palpitation (hartklopping), panic (paniek), tens (spanning), crowd (menigte), dyspnea (ademnood), nerves (zenuwen)

Pain-related: Physician (dokter), wheelchair (rolstoel), disabled (invalide), bandage (verband), diagnosis (diagnose), hospital (ziekenhuis)

Social-evaluation-related: Stranger (vreemde), criticism (kritiek), shame (schaamte), rejection (afwijzing), impression (indruk), acceptation (acceptatie)

Attribute Threat: Fatal (fataal), threatening (dreigend), dangerous (gevaarlijk), words
Health-threatening: Physician (dokter), blood (bloed), infection (infectie), disabled (invalide), cancer (kanker), wound (wond)

Threatening: Burglary (inbraak), hate (haat), war (oorlog), hold-up (overval), terrorism (terrorisme), violence (geweld) 
Appendix A. (continued)

STUDY 1

Neutral: Customary (gewoon), neutral (neutraal), objective

(objectief), adult (volwassen), oval (oval), modern (modern)
STUDY 2

Safe: Hug (knuffel), nice (lief), home (thuis), enjoyable (gezellig), friendship (vriendschap), fortune (geluk)

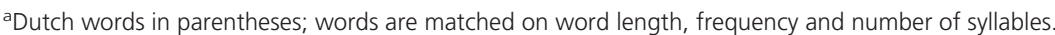

\section{Appendix B. The Situational Descriptions, Formulated in the Vignettes Assessing the Engagement in Health Protecting Behavior, Divided in Medical Help Seeking Behavior and Escape/Avoidance Behavior}

Medical Help SeEking BeHAVIOR

\begin{tabular}{|c|c|c|}
\hline & SITUATION & BEHAVIOR \\
\hline 1 & Falling while walking in your socks. Break the fall on your wrists. Your wrist hurts & Visiting a GP to have your wrist examined \\
\hline 2 & Girl in the neighborhood has meningitis. You spoke to her 2 weeks ago & Visiting a GP for preventive medication \\
\hline 3 & Employer offers opportunity for free medical check-up & Participate in the medical check-up \\
\hline 4 & $\begin{array}{l}\text { Wisdom tooth needs to be removed. You received a prescription to purchase } \\
\text { analgesics before the procedure, even if probably not necessary }\end{array}$ & Purchase the analgesics \\
\hline 5 & $\begin{array}{l}\text { Sudden stomach pain during the weekend. Own GP is unreachable, possible to } \\
\text { visit unfamiliar GP }\end{array}$ & Visit the unfamiliar GP \\
\hline 6 & Reading about birthmarks on the internet and their possible health danger & Having the spots examined \\
\hline \multicolumn{3}{|c|}{ ESCAPEIAVOIDANCE BEHAVIOR } \\
\hline \multicolumn{2}{|r|}{ SITUATION } & BEHAVIOR \\
\hline 7 & Hearing about SARS in China after you have booked a trip to China & Still traveling to China as planned* \\
\hline 8 & $\begin{array}{l}\text { Few weeks ago you twisted your ankle. This has healed; friends ask if you want } \\
\text { to go indoor skiing with them }\end{array}$ & Agree to go skiing with friends* \\
\hline 9 & $\begin{array}{l}\text { Legionella bacterium discovered in thermal baths. After cleaning of the water } \\
\text { pipes the baths are open for visitors again }\end{array}$ & $\begin{array}{l}\text { Visiting the thermal baths one week after } \\
\text { re-opening* }\end{array}$ \\
\hline 10 & $\begin{array}{l}\text { Reading about chemical substance in your favorite diet drink that heightens the } \\
\text { risk at cancer }\end{array}$ & Drink less of your favorite drink \\
\hline 11 & $\begin{array}{l}\text { Once in a while problems with your knee. Family members ask if you will join } \\
\text { them in a long walk }\end{array}$ & Wearing a supportive brace for your knee \\
\hline 12 & Anti-RSI adaptations at work. At home you work at the computer for your hobby & Use anti-RSI adaptations at home \\
\hline
\end{tabular}

*Reversely scored items. 